\title{
Papers
}

\section{Benzodiazepine use in pregnancy and major malformations or oral cleft: meta-analysis of cohort and case-control studies}

\author{
Lisa R Dolovich, Antonio Addis, J M Régis Vaillancourt, J D Barry Power, Gideon Koren, \\ Thomas R Einarson
}

\begin{abstract}
Objective: To determine if exposure to benzodiazepines during the first trimester of pregnancy increases risk of major malformations or cleft lip or palate.

Design: Meta-analysis.

Setting: Studies from 1966 to present.

Subjects: Studies were located with Medline, Embase, Reprotox, and from references of textbooks, reviews, and included articles. Included studies were original, concurrently controlled studies in any language.

Interventions: Data extraction and quality assessment were done independently and in duplicate.

Main outcome measures: Maternal exposure to benzodiazepines in at least the first trimester; incidence of major malformations or oral cleft alone, measured as odds ratios and 95\% confidence intervals with a random effects model.

Results: Of over 1400 studies reviewed, 74 were retrieved and 23 included. In the analysis of cohort studies fetal exposure to benzodiazepine was not associated with major malformations (odds ratio 0.90; $95 \%$ confidence interval 0.61 to 1.35 ) or oral cleft (1.19; 0.34 to 4.15$)$. Analysis of case-control studies showed an association between exposure to benzodiazepines and development of major malformations $(3.01 ; 1.32$ to 6.84$)$ or oral cleft alone (1.79; 1.13 to 2.82$)$.

Conclusions: Pooled data from cohort studies showed no association between fetal exposure to benzodiazepines and the risk of major malformations or oral cleft. On the basis of pooled data from case-control studies, however, there was a significant increased risk for major malformations or oral cleft alone. Until more research is reported, level 2 ultrasonography should be used to rule out visible forms of cleft lip.
\end{abstract}

\section{Introduction}

Benzodiazepines are commonly used for anxiety, insomnia, and epilepsy. Their use is substantial, even by pregnant women. Bergman et al found that $2 \%$ of pregnant women in the United States who were receiving Medicaid benefits filled one or more prescriptions for benzodiazepines during pregnancy. ${ }^{1}$ As about half of pregnancies in the United States are unplanned, ${ }^{2}$ many women may inadvertently expose the fetus to benzodiazepines during the first trimester. Therefore, women require valid information regarding the risks of benzodiazepine use during pregnancy to avoid exposure to teratogens but also to ensure that they are not denied medication during pregnancy because of unfounded fear of unknown consequences.

Antepartum exposures to benzodiazepines have been associated with teratogenic effects (for instance, facial cleft, skeletal anomalies) in some animal studies ${ }^{34}$ but not others. ${ }^{56}$ Early case-control studies in humans found that maternal benzodiazepine exposure increased the risk of fetal cleft lip and cleft palate. ${ }^{78}$ Subsequent reports implicated benzodiazepines as the cause of major malformations ${ }^{9-11}$ and a benzodiazepine syndrome similar to fetal alcohol syndrome. ${ }^{912}{ }^{13}$ Numerous studies, however, have refuted these findings. ${ }^{14-16}$ These contradictory results have led to considerable controversy surrounding the use of benzodiazepines in pregnancy. We carried out a metaanalysis to examine whether exposure to benzodiazepines during at least the first trimester is associated with increased risk of major malformations or oral cleft.

\section{Methods}

\section{Data sources}

We systematically searched Medline (1966 to December 1997 via Ovid), Embase (1980 to December 1997), Reprotox (a database of reviews on reproductive toxicity topics), references in textbooks on drugs in pregnancy, references of included studies, and review articles. "Benzodiazepine(s)" (exploded as a subject heading or the various preparations put in as textwords) was combined with the following words as subject headings or textwords: fetal diseases, infant, fetal organ maturity, cleft lip, cleft palate, major malformations, and prenatal exposure.

The Toronto based MotheRisk Program, a consultation service for drug, chemical, and radiation exposure during pregnancy, helped to locate unpublished papers and provided one unpublished study and
Faculty of
Pharmacy,
University of
Toronto, Toronto,
Ontario, Canada
M5S 2S2
Lisa Dolovich,
PharmD candidate 
one abstract. The original authors provided unpublished data.

\section{Study selection}

Searches were reviewed or completed independently and in duplicate. Cohort or case-control studies in any language considered pertinent were retrieved and included if they examined the relation between human maternal exposure to benzodiazepines in at least the first trimester and major malformations or oral cleft alone and included an unexposed concurrent control group. Major malformations were those described by Heinonen et al, which, among others, include cleft palate and cleft lip. ${ }^{17}$ Hereafter "oral cleft" is used for cleft lip or cleft palate, or both. Studies examining only certain subtypes of malformations or studies in patients with epilepsy were included but considered separately from the main analysis. Only studies where exposure occurred during the first trimester were considered as the fetus is most susceptible to teratogens during the period between the 1st and 8th weeks of organogenesis, the lip forms between weeks 4 and 8 , and the oral palate forms between weeks 5 and 12. Studies were excluded if they were case series or reports, editorials, reviews, animal studies or used only stillbirths or abortions or the data could not be extracted.

All published studies deemed suitable were retrieved. Unpublished studies were treated methodologically in the same way as published studies. The methods sections with study identifiers removed were reviewed independently and in duplicate to determine inclusion. Consensus or a third party whose decision was final resolved disagreements.

\section{Data extraction}

Once the study was included data were extracted and quality assessed independently and in duplicate. Discrepancies were resolved through consensus. Study quality was assessed by using predetermined criteria. These aspects of study quality are provided in the results section as descriptive information.

Table 1 Association of major malformations in fetuses with prenatal benzodiazepine exposure

\begin{tabular}{|c|c|c|c|c|c|}
\hline \multirow[b]{2}{*}{ First author (year) } & \multicolumn{2}{|c|}{ Exposed } & \multicolumn{2}{|c|}{ Not exposed } & \multirow[b]{2}{*}{ Odds ratio $(95 \% \mathrm{CI})$} \\
\hline & No malformed & Total & No malformed & Total & \\
\hline \multicolumn{6}{|l|}{ Cohort studies } \\
\hline \multicolumn{6}{|l|}{ Non-epileptic patients: } \\
\hline Milkovich (1974) ${ }^{11}$ & 5 & 86 & 10 & 229 & $1.35(0.45$ to 4.07$)$ \\
\hline Crombie $(1975)^{23}$ & 3 & 200 & 382 & 19143 & 0.75 (0.24 to 2.35$)$ \\
\hline Hartz $(1975)^{14}$ & 11 & 257 & 2179 & 46233 & 0.90 (0.49 to 1.66$)$ \\
\hline Kullander $(1976)^{24}$ & 2 & 89 & 198 & 5664 & $0.63(0.16$ to 2.60$)$ \\
\hline Laegreid $(1992)^{25}$ & 1 & 17 & 1 & 29 & $1.75(0.10$ to 29.92$)$ \\
\hline Pastuszak $(1996)^{26}$ & 1 & 106 & 3 & 115 & 0.36 (0.04 to 3.47$)$ \\
\hline Ornoy $(1997)^{27}$ & 9 & 335 & 10 & 363 & 0.97 (0.39 to 2.43 ) \\
\hline Combined effect & & & & & $0.90(0.61 \text { to } 1.35)^{*}$ \\
\hline \multicolumn{6}{|l|}{ Epileptic patients: } \\
\hline Nakane $(1980)^{30}$ & 16 & 117 & 42 & 490 & 1.69 (0.91 to 3.13$)$ \\
\hline Robert $(1986)^{31}$ & 0 & 4 & 8 & 144 & $1.78(0.09$ to 35.94$)$ \\
\hline \multicolumn{6}{|l|}{ Case-control studies } \\
\hline Greenberg $(1977)^{29}$ & 36 & 60 & 800 & 1612 & 1.52 (0.9 to 2.58$)$ \\
\hline Bracken $(1981)^{28}$ & 39 & 72 & 1331 & 4266 & 2.61 (1.63 to 4.16$)$ \\
\hline Noya $(1981)^{32}$ & 1 & 24 & 0 & 24 & $3.13(0.12$ to 80.68$)$ \\
\hline Laegreid $(1990)^{13}$ & 8 & 10 & 10 & 68 & 23.20 (4.29 to 125.55$)$ \\
\hline Combined effect & & & & & 3.01 (1.32 to 6.84$) \dagger$ \\
\hline
\end{tabular}

Data analysis

Studies of different design-namely, cohort and case-control studies-were analysed separately because of differing threats to their internal validity. ${ }^{18}{ }^{19}$ Data were analysed by calculating the odds ratio and 95\% confidence interval with a random effects model. ${ }^{20} \mathrm{We}$ also calculated $\chi^{2}$ tests for heterogeneity. ${ }^{21}$ Further sensitivity analyses were performed for case-control studies to assess the impact of recall bias through the use of normal babies compared with malformed babies as controls.

In a further examination of homogeneity of effects we plotted the data with the rates of malformations in the control groups on the $\mathrm{X}$ axis and in the exposed subjects on the $\mathrm{Y}$ axis as suggested by L'Abbé et al. ${ }^{22} \mathrm{We}$ first visually inspected the plot for evidence of obvious outliers. We then regressed the malformation rate in the exposed group on that of the controls. The slope of that regression line was compared with the null hypothesis (that is, a slope of 1) by using standard techniques as a test for effects. We also examined residuals to determine if any observations were outliers (that is, $>1.96 \mathrm{SE}$ ) from a statistical point of view. Publication bias was examined through visual inspection of a funnel plot whereby odds ratios were plotted against study sample size.

\section{Results}

Over 1400 studies were considered. Most were not retrieved because two independent reviewers considered that they did not relate to the question under review. Of the studies considered, 74 studies were retrieved and 51 of these were excluded. Studies were excluded because they had no concurrent control group (18), they did not examine major malformations (9), they were carried out on animals (1), benzodiazepines were not studied (1), exposure was not during the first trimester (1), studies were review articles or commentaries (5), data presented were duplicated in an included trial (6), results for benzodiazepines were not reported separately from other agents (5), only a range of results were reported (1), only partial data were provided (2), benzodiazepine exposure was not linked to malformations (1), and the study was not available in North America (1). A complete list of excluded studies is available from the authors. Thirteen studies that examined major malformations, ${ }^{11} 1314$ 23-32 11 studies that examined oral cleft alone, , 71013273031 33-36 and three studies that examined other specific malformations ${ }^{37-39}$ were included (some providing information for more than one evaluation). One study unpublished at the time of consideration has since been published. ${ }^{26}$

Of the 23 included studies, $20(87 \%)$ predefined exposure $^{1101113142325-2830-39}$ and $22(96 \%)$ predefined the outcome. ${ }^{171011} 131423$ 25-32 34-40 Exposure was ascertained mainly through interview with the mother (61\% of studies) $)^{7} 10^{145-30333436-38}$ and outcome was confirmed mainly by using physician examination or records (44\% of studies) $)^{11} 131425283032343940$ or malformation registries (30\% of studies)..$^{7} 29$ 31 35-37 Equal diagnostic examination between exposed and unexposed groups occurred in all but three studies. ${ }^{142535}$ Hartz et al gathered and confirmed information about malformed babies from different sources but did not do so for control babies. ${ }^{14}$ Czeizel et al sent surveys to 
up to three controls if initial controls did not respond..$^{35}$ Laegreid et al used blood samples to confirm benzodiazepine exposure and had blood sample results for $78 \%$ of cases but only $66 \%$ of controls. ${ }^{25}$

Various benzodiazepines were used or prescribed, although $48 \%$ of the studies $(11 / 23)$ examined the use of chlordiazepoxide or diazepam only. ${ }^{1011} 14232830$ 32-34 3740 Only two studies provided any information regarding the duration of maternal exposure..$^{25}{ }^{26}$ The indications for use were infrequently provided. ${ }^{11} 252641$ Sixty one percent (14/23) of studies reported concurrent use of at least some prescription medications. ${ }^{1} 1011132526$ 28-32 37-39

\section{Associations with major malformations}

Data pooled from seven cohort studies did not show an association between fetal exposure to benzodiazepines during pregnancy and major malformations (odds ratio $0.90 ; 95 \%$ confidence interval 0.61 to 1.35 ; homogeneity $\chi^{2}=1.74 ; \mathrm{P}=0.62$; table 1 , figure 1$) .{ }^{11}{ }^{14}{ }^{23-27}$ Two cohort studies carried out in patients with epilepsy were located. Results of both were not significant. ${ }^{30}{ }^{31}$

Combination of four case-control studies showed that major malformations were associated with the use of benzodiazepines during pregnancy $(3.01 ; 1.32$ to $\left.6.84 ; \chi^{2}=9.87 ; \mathrm{P}=0.008\right) .{ }^{13} 282932$ All included casecontrol studies that evaluated major malformations used normal babies as controls so subgroup analyses based on types of controls could not be done. Regression analyses for both cohort and case-control studies showed no obvious heterogeneity.

\section{Associations with oral cleft}

Data pooled from three cohort studies showed no relation between fetal exposure to benzodiazepines during pregnancy and oral cleft $\left(1.19 ; 0.34\right.$ to $4.15 ; \chi^{2}=0.01$; $\mathrm{P}=0.997$; table 2, figure 2). ${ }^{1273}$ The analysis of six case-control studies produced a significant odds ratio for oral cleft of 1.79 (1.13 to $2.82 ; \chi^{2}=11.39$ $\mathrm{P}=0.01)^{710^{13} 3^{34-36}}$ Subgroup analysis of the casecontrol studies with normal babies as controls showed no significant association with oral cleft $(1.63 ; 0.89$ to $\left.2.96 ; \chi^{2}=3.81 ; \mathrm{P}=0.15\right) .{ }^{7355}$ Similarly, no significant association was found in analyses of case-control studies with malformed babies as controls $(2.03 ; 0.88$ to $\left.4.71 ; \chi^{2}=6.90 ; \mathrm{P}=0.10\right) .{ }^{1034}{ }^{36}$ Regression analyses for both cohort and case-control studies showed no obvious heterogeneity.

In general, for the analyses of major malformation and oral cleft the risks for case-control studies were grouped at a different end of the distribution than the risks for cohort studies, showing that the relative risks within each study design are of the same magnitude but the absolute differences in risk are of a different order of magnitude between studies (case-control about 10 times greater than cohort). This finding suggests a possible systematic difference between study designs. Funnel plot analyses produced funnel shaped plots, indicating that there was no obvious publication bias.

Two case-control studies examined the association of benzodiazepine use with fetal cardiac malformations. One showed no association between exposure and outcome; the other did. ${ }^{37}$ One study examined benzodiazepine use with malformations of the central

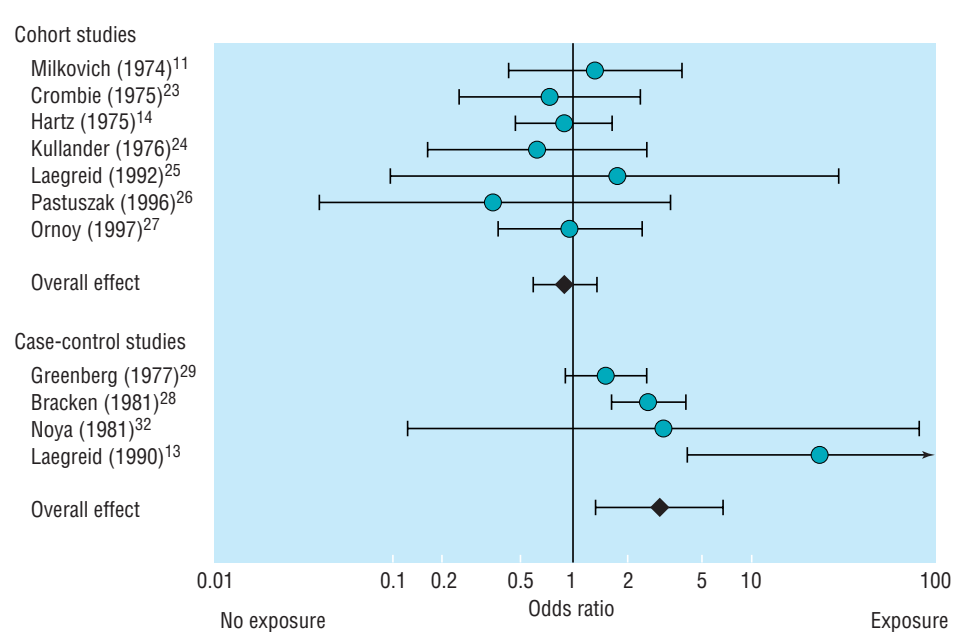

Fig 1 Association of major malformations with prenatal exposure to benzodiazepines

Table 2 Results of studies examining association of specific malformations with prenatal exposure to benzodiazepines

\begin{tabular}{|c|c|c|c|c|c|}
\hline \multirow[b]{2}{*}{ Author (year) } & \multicolumn{2}{|c|}{ Exposed } & \multicolumn{2}{|c|}{ Not exposed } & \multirow[b]{2}{*}{ Odds ratio $(95 \% \mathrm{Cl})$} \\
\hline & $\begin{array}{c}\text { No } \\
\text { malformed }\end{array}$ & Total & $\begin{array}{c}\text { No } \\
\text { malformed }\end{array}$ & Total & \\
\hline \multicolumn{6}{|c|}{ Cohort studies (oral cleft) } \\
\hline \multicolumn{6}{|c|}{ Non-epileptic patients: } \\
\hline Shiono $(1984)^{33}$ & 1 & 854 & 31 & 32395 & $1.22(0.17$ to 8.98$)$ \\
\hline Bergman $(1992)^{1}$ & 0 & 1354 & 62 & 102985 & $1.21(0.17$ to 8.71$)$ \\
\hline Ornoy $(1997)^{27}$ & 0 & 335 & 0 & 363 & $1.08(0.07$ to 17.39$)$ \\
\hline Combined effect & & & & & $1.19(0.34 \text { to } 4.15)^{*}$ \\
\hline \multicolumn{6}{|l|}{ Epileptic patients: } \\
\hline Nakane $(1980)^{30}$ & 3 & 117 & 12 & 490 & 1.05 (0.29 to 3.78$)$ \\
\hline Robert $(1986)^{31}$ & 0 & 4 & 1 & 144 & 10.63 (0.38 to 298.57$)$ \\
\hline
\end{tabular}

Case-control studies

Oral cleft:

\begin{tabular}{|c|c|c|c|c|c|}
\hline Safra $(1975)^{10}$ & 7 & 16 & 42 & 262 & $4.07(1.44$ to 11.54$)$ \\
\hline Saxen $(1975)^{7}$ & 27 & 40 & 511 & 1044 & 2.17 (1.11 to 4.24$)$ \\
\hline Rosenberg $(1983)^{34}$ & 13 & 67 & 590 & 3011 & 0.99 (0.54 to 1.82$)$ \\
\hline Rodriguez $(1986)^{36}$ & 8 & 61 & 442 & 7990 & 2.58 (1.22 to 5.45$)$ \\
\hline Czeizel $(1987-88)^{35}$ & 48 & 91 & 1153 & 2311 & $1.12(0.74$ to 1.71$)$ \\
\hline Laegreid $(1990)^{13}$ & 2 & 10 & 4 & 68 & $4.00(0.63$ to 25.43$)$ \\
\hline Combined effect & & & & & $1.79(1.13$ to 2.82$) \dagger$ \\
\hline \multicolumn{6}{|l|}{ Cardiac malformations: } \\
\hline Tikkanen $(1992)^{37}$ & 2 & 10 & 404 & 1152 & $0.46(0.10$ to 2.19$)$ \\
\hline Correa-Villasenor $(1994)^{38}$ & 57 & 92 & 3318 & 6855 & 1.74 (1.14 to 2.65$)$ \\
\hline \multicolumn{6}{|c|}{ Malformations of central nervous system: } \\
\hline Winship $(1984)^{39}$ & 14 & 750 & 14 & 750 & 1.00 (0.47 to 2.11$)$ \\
\hline
\end{tabular}

${ }^{*} \chi^{2}=0.01 ; P=0.997$

$\dagger \chi^{2}=11.39 ; P=0.01$

nervous system and did not find any association between exposure and outcome. ${ }^{39}$

\section{Discussion}

Data taken from cohort studies showed no significant association between benzodiazepines taken during the first trimester and either major malformations or malformations of the oral cleft alone. However, data from case-control studies showed a small but significant increased risk for these events. This finding may reflect the substantially higher sensitivity of case-control studies to examine the risk of specific malformations or it may be chance.

The tests of heterogeneity also showed that the cohort studies were not heterogeneous for both major 


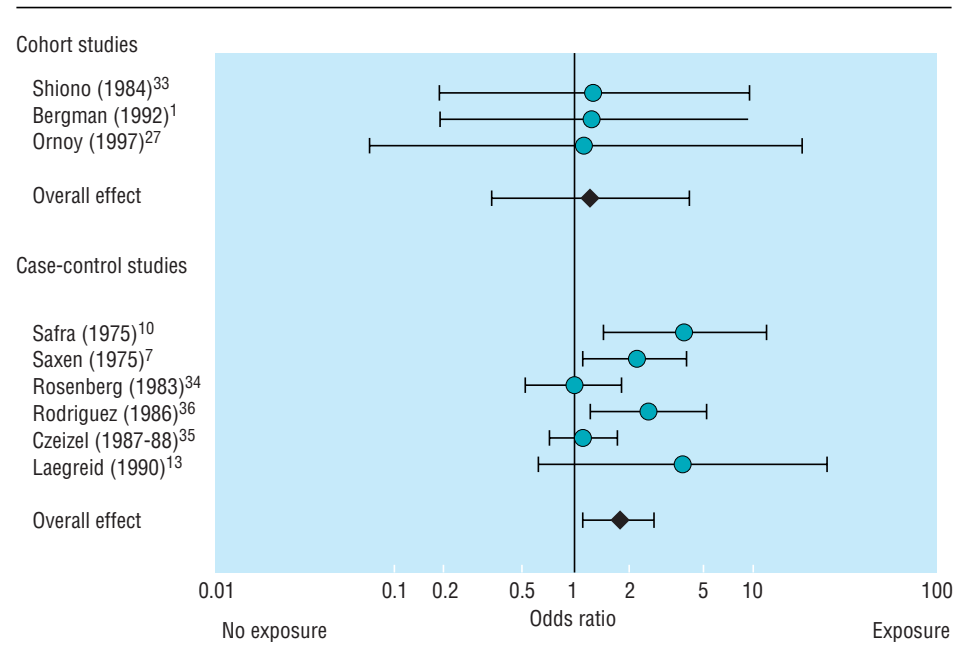

Fig 2 Association of oral cleft with prenatal exposure to benzodiazepines

malformation and oral cleft, whereas the case-control studies for oral cleft were heterogeneous, which decreases the reliability of these marginally significant results.

A case series of eight children exposed to benzodiazepines in utero suggested the existence of a benzodiazepine syndrome. ${ }^{9}$ This syndrome was described as dysmorphic features, growth aberrations, and abnormalities of the central nervous system. ${ }^{9}{ }^{12}{ }^{13}$ Our results, however, do not confirm the presence of this syndrome. Even before this report alternative causes for these findings, such as Zellweger syndrome or other genetic abnormalities, have been suggested. ${ }^{42}$

\section{Possible confounding and bias}

Concomitant exposure to other medications can result in an overestimation of the risk of benzodiazepines. Fourteen studies, eight of which were case-control, allowed exposure to other potentially teratogenic medications. ${ }^{1} 11113252628-32$ 37-39 This large number confounds the results. In most studies no information on duration or indication for use of benzodiazepines was provided. Therefore it was difficult to determine if any of the populations included have an increased or decreased risk of major malformations. Studies that evaluated the risk of fetal malformations in women with epilepsy were separated from the main analysis as fetuses born to such women already have an increased risk of major malformations. ${ }^{43}$ Information is lacking regarding the risk of developing specific malformations.

The use of a normal baby as a control in a case-control study can produce recall bias, as mothers of malformed babies may be more likely to recall exposures than mothers of normal babies. The subgroup analysis that compared benzodiazepine use in mothers of healthy babies as controls compared with mothers of malformed babies as controls produced similar effect sizes, suggesting that recall bias did not have a large effect on study outcome.

The present meta-analysis has several limitations. The number of reports was relatively small and may have limited the power of our analysis. Also, although the overall sample was large, most cases for analyses of both oral cleft and major malformations were derived from only three studies. ${ }^{14}{ }^{23}$ With regard to assessment
- Pooled data from cohort studies showed no apparent association between fetal exposure to benzodiazepines and the risk for major malformations or oral cleft

- Data from case-control studies showed that risk for major malformations or oral cleft alone was increased

- Until more studies are done, it is prudent to perform level 2 ultrasonography to rule out visible forms of cleft lip

of malformations, the studies used wide ranging definitions for identification of malformations to be considered. When we examined the association of benzodiazepines with cleft lip and cleft palate we had to combine these two malformations as "oral cleft" because many studies combined these malformations as one entity and it was not possible to stratify the data. ${ }^{10} 1336$

This study differs from previous reviews. Altshuler et al reported an association between benzodiazepines and oral cleft, but the review included studies that did not have any control groups or studies that did not have concurrent control groups. ${ }^{44}$ That method of analysis may have seriously increased the strength of association found and the heterogeneity found when studies were combined and thereby produced different results. McElhatton provided a narrative review that succinctly summarised the opposing information, but because the studies presented were not combined systematically or quantitatively the conclusions remain controversial and inconclusive. $^{45}$

\section{Conclusions}

Because women commonly use benzodiazepines and half of all pregnancies are unplanned, counselling of women on the safety of such exposure is clinically important. Pooled data from cohort studies showed no apparent association between benzodiazepine use and the risk for major malformations or oral cleft alone. There was, however, a small but significantly increased risk for oral cleft according to data from the available case-control studies. More case-control studies examining these events are needed especially because the available studies are not homogeneous. Even when the "worst case scenario" is assumed, benzodiazepines do not seem to be major human teratogens, but because some cases of cleft lip can be visualised by fetal ultrasound level 2 ultrasonography should be used to rule out this malformation.

This project was completed as part of a requirement for a doctor of pharmacy course on critical appraisal, PHM 605, at the University of Toronto.

Contributors: LRD coordinated the study, including discussion of core ideas, design of study, information retrieval, study selection, data extraction, statistical analysis, data analysis and interpretation, and writing the paper; AA participated in discussion of core ideas, design of study, sugy selection, data extraction, data nalaysi and interpretation, and editing the paper; JMRV and JDBP participated in discussion of core ideas, designing the study, information retrieval, study selection, data extraction, and writing the paper; GK and TRE helped initiate the project, participated in research design, analysis and 
intepreatation and in editing the paper. LD will act as guarantor for the study.

Funding: No additional funding.

Conflict of interest: None

1 Bergman U, Rosa FW, Baum C, Wiholm BE, Faich GA. Effects of exposure to benzodiazepine during fetal life. Lancet 1992;340:694-6.

2 Skrabanek P. Smoking and statistical overkill. Lancet 1992;340:1208-9.

3 Miller RP, Becker BA. Teratogenicity of oral diazepam and diphenylhydantoin in mice. Toxicol Appl Pharmacol 1975;32:53-61.

4 Walker BE, Patterson A. Induction of cleft palate in mice by tranquillizers and barbiturates. Teratology 1974;10:159-63.

5 Beall JR. Study of the teratogenic potential of oral diazepam and SCH 12041. Can Med Assoc J 1972;106:1061.

6 Chesley S, Lumpkin M, Schatzki A, Galpern WR, Greenblatt DJ, Shader RI, et al. Prenatal exposure to benzodiazepine. I. Prenatal exposure to lorazepam in mice alters open-field activity and GABA receptor function. Neuropharmacology 1991;30:53-8.

7 Saxen I, Saxen L. Association between maternal intake of diazepam and oral clefts. Lancet 1975;ii:498

Saxen I, Lahti A. Cleft lip and palate in Finland: incidence, secular, seasonal, and geographical variations. Teratology 1974;9:217-24.

9 Laegreid L, Olegard R, Walstrom J, Conradi N. Teratogenic effects of benzodiazepine use during pregnancy. J Pediatr 1989;114:126-31.

10 Safra MJ, Oakley GP. Association between cleft lip with or without cleft palate and prenatal exposure to diazepam. Lancet 1975;ii:478-80.

11 Milkovich L, van den Berg BJ. Effects of prenatal meprobamate and chlor diazepoxide hydrochloride on human embryonic and fetal development N Engl J Med 1974;291:1268-71.

12 Laegreid L, Olegard R, Wahlstrom J, Conradi N. Abnormalities in children exposed to benzodiazepines in utero. Lancet 1987;i:108-9.

13 Laegreid L, Olegard R, Conradi N, Hagberg G, Wahlstrom J, Abrahamsson L. Congenital malformations and maternal consumption of benzodiazepines: a case-control study, Dev Med Child Neurol 1990;32:432-41.

14 Hartz SC, Heinonen OP, Shapiro S, Siskind V, Slone D. Antenatal exposure to meprobamate and chlordiazepoxide in relation to malformations, mental development, and childhood mortality. $N$ Engl J Med 1975;292:726-8.

15 St Clair SM, Schirmer RG. First trimester exposure to alprazolam. Obstet Gynecol 1992;80:843-6.

16 Jick H, Holmes LB, Hunter JR, Madsen S, Stergachis A. First trimester drug use and congenital disorders. JAMA 1981;246:343-6.

17 Heinonen OP, Sloane D, Shapiro S. Birth defects and drugs in pregnancy: maternal drug exposure and congenital malformations. Littleton, Massachusetts: Publishing Sciences Group, 1977.

18 Horwitz RI, Feinstein AR. Methodologic standards and contradictory results in case-control research. Am J Med 1979;66:556-64.

19 Levine M, Walter S, Lee H, Haines T, Holbrook A, Moyer V. Users' guides to the medical literature. IV. How to use an article about harm. JAMA 1994:271:1615-9.

20 DerSimonian R, Laird N. Meta-analysis in clinical trials. Cont Clin Trials $1986 ; 7: 177-88$

21 Fleiss JL. The statistical basis of meta-analysis. Stat Methods Med Res 1993;2:121-45.

22 L'Abbe KA, Detsky AS, O'Rourke K. Meta-analysis in clinical research. Ann Intern Med 1987;107:224-33.

23 Crombie DL, Pinsent RJ, Fleming DM, Rumeau-Rouquette C, Goujard J, Huel G. Fetal effects of tranquilizers in pregnancy. $N$ Engl $J$ Med $1975 ; 293: 198-9$

24 Kullander S, Kallen B. A prospective study of drugs and pregnancy. I Psychopharmaca. Acta Obstet Gynecol Scand 1976;55:25-33.
25 Laegreid L, Hagberg G, Lundberg A. Neurodevelopment in late infancy after prenatal exposure to benzodiazepines-a prospective study. Neuropediatrics 1992;23:60-7.

26 Pastuszak A, Milich V, Chan S, Chu J, Koren G. Prospective assessment of pregnancy outcome following first trimester exposure to benzodiazepines. Can J Clin Pharmacol 1996;3:167-71.

27 Ornoy A, Moerman L, Lukashova I, Arnon J. The outcome of children exposed in-utero to benzodiazepines. Teratology 1997;55:102A.

28 Bracken MB, Holford TR. Exposure to prescribed drugs in pregnancy and association with congenital malformations. Obstet Gynecol $1981 ; 58: 336-44$

29 Greenberg G, Inman WH, Weatherall JA, Adelstein AM, Haskey JC. Maternal drug histories and congenital abnormalities. BMJ 1977;ii:853-6.

30 Nakane Y, Okuma T, Takahashi R, Sato Y, Wada T, Sato T, et al Multi-institutional study on the teratogenicity and fetal toxicity of antiepileptic drugs: a report of a collaborative study group in Japan. Epilepsia 1980;21:663-80.

31 Robert E, Lofkvist E, Mauguiere F, Robert JM. Evaluation of drug therapy and teratogenic risk in a Rhone-Alpes district population of pregnant epileptic women. Eur Neurol 1986;25:436-43.

32 Noya CA. Epidemiological study on congenital malformations. Rev Cubana Hig Epidemiol 1981;19:200-10.

33 Shiono PH, Mills JL. Oral clefts and diazepam use during pregnancy. $N$ Engl J Med 1984;311:919-20.

34 Rosenberg L, Mitchell AA, Parsells JL, Pashayan H, Louik C, Shapiro S Lack of relation of oral clefts to diazepam use during pregnancy. $N$ Engl J Med 1983;309:1282-5.

35 Czeizel A. Lack of evidence of teratogenicity of benzodiazepine drugs in Hungary. Reprod Toxicol 1987-88;1:183-8.

36 Rodriguez PE, Salvador PJ, Garcia AF, Martinez FM. Relationship between benzodiazepine ingestion during pregnancy and oral clefts in the newborn: a case-control study. Med Clin 1986;87:741-3.

37 Tikkanen J, Heinonen OP. Congenital heart disease in the offspring and maternal habits and home exposures during pregnancy. Teratology 1992;46:447-54

38 Correa-Villasenor A, Ferencz C, Neill CA, Wilson PD, Boughman JA Ebstein's malformation of the tricuspid valve: genetic and environmental factors. Teratology 1994;50:137-47.

39 Winship KA, Cahal DA, Weber JP, Griffin JP. Maternal drug histories and central nervous system anomalies. Arch Dis Child 1984;59:1052-60.

40 Gregroire G, Derderian F, LeLorier J. Selecting the language of the publications included in a meta-analysis: is there a tower of Babel bias? Pharmacoepidemiol Drug Safety 1994;3:S18.

41 Viggedal G, Hagberg BS, Laegreid L, Aronsson M. Mental development in late infancy after prenatal exposure to benzodiazepines-a prospective study. J Child Psychol Psychiatry 1993;34:295-305.

42 Winter RM. In utero exposure to benzodiazepines. Lancet 1987;i:627.

43 Samrem EB, van Duijn CM, Hiilesmaa VK, Klepel H, Bardy AH, Mannagetta GB, et al. Maternal use of antiepileptic drugs and the risk of major congenital malformations: a joint European prospective study of human teratogenesis associated with maternal epilepsy. Epilepsia 1997;38:981

44 Altshuler LL, Cohen L, Szuba M, Burt VK, Gitlin M, Mintz J. Pharmacologic management of psychiatric illness during pregnancy: dilemmas and guidelines. Am J Psychiatry 1996;153:592-606.

45 McElhatton PR. The effects of benzodiazepine use during pregnancy and lactation. Reprod Toxicol 1994;8:461-75.

(Accepted 11 June 1998)

\section{One hundred years ago A dangerous custom at funerals}

Sir,-I venture to draw attention to the evil consequences, of which most medical men could give instances, that often follow attendance at funerals during inclement weather, and at a time when the nervous systems of the mourners and others are depressed. Careful attention to clothing and every means of protection may ward off many of the dangers arising from cold, wet, and boisterous weather; but when all is done, there remains an ordeal dreaded by many-that of standing bareheaded at the grave, it may be in a blazing sun or, what in this climate is more common, in a pitiless, cold, and biting wind.

We sometimes read such remarks as these: "The large assemblage, heedless of the piercing, cold blasts, stood uncovered throughout the whole ceremony." When we reflect on the numbers that are doing this daily, not in the metropolis alone, but all over the British Isles, there cannot but be a vast amount of suffering, mental and bodily, to say the very least.
As this dangerous exposure is dictated by reverence, it seems a delicate matter to challenge its necessity among a people so conservative of habits and customs relating to the dead; but surely a way might be found to obviate danger without abating reverence. Occasionally one sees an individual, made bold perhaps by some conscious weakness, or some bitter experience, donning a skull cap as he doffs the obtrusive chimney-pot, while many, no doubt, wish they could follow suit.

If only some influential persons would lead the way-and who could do this better, by example and precept, than medical men?-it would soon become the custom to go provided with a pocket head covering-if only a black handkerchief- just as one does with a pair of gloves. - I am, etc,

London, Dec 26th, 1897. Pilgrim. (BMJ 1898;i:50) 